\title{
New developments in financial statement analysis. Liquidity in the winery sector
}

\author{
Núria Arimany-Serrat ${ }^{\mathrm{a}}$, M. Àngels Farreras-Noguer ${ }^{\mathrm{b}}$ and Germà Coenders ${ }^{\mathrm{c}}$
}

${ }^{a}$ Department of Economics and Business, University of Vic-Central University of Catalonia, Spain ${ }^{b}$ Department of Business Administration, University of Girona, Spain

cDepartment of Economics, University of Girona, Spain

\section{H R O N I C L E}

Article history:

Received June 1, 2021

Received in revised format

September 202021

Accepted October 72021

Available online

October 72021

Keywords:

Compositional data (CoDa)

Financial statement analysis

Spanish wine industry

Liquidity

Statement of cash flows

Financial ratios

\section{A B S T R A C T}

The aim of this article is to analyse the short-term solvency of large companies in the wine sector in the period 2014-2018, in two relevant Spanish wine-production areas and assess significant differences in time and between regions. Liquidity is a direct threat to the financial health of companies and is analysed using standard financial indicators and compositional data, in order to prevent the common outlier, non-linearity and asymmetry problems in standard financial ratios. The study shows that the compositional ratios are statistically more adequate and that the turnover indicator between operating cash inflows with respect to current investments and operating cash outflows with respect to current liabilities is a complementary indicator to standard cash flow ratios. Wineries in La Rioja have better liquidity than Catalan wineries in the period under study.

\section{Introduction}

The survival of companies in the wine sector is linked to several variables including marketing and distribution channels (Alonso \& Liu, 2012) and a balance between domestic sales and exports (Simon-Elorz et al., 2010). Other authors show that profitability and productivity are key to the quality wine segment (Sellers-Rubio, 2010). However, the crucial variable for both firm survival and growth is liquidity (Guariglia et al., 2011). In order to strengthen this variable, the measures adopted by European and national regulations consider the difficulties that the sector is going through. The Spanish Royal Decree 557/2020, of June 9, 2020, or the Commission Delegated Regulation (EU) 2020/592, of April 30, 2020, aim at injecting liquidity to wineries that meet certain requirements. The aim of this article is to present a novel approach to the analysis of liquidity in the wine sector, during a period of five years (2014-2018), in two relevant wine production areas with different characteristics in Spain, in order to assess the short-term solvency of companies. Although financial ratios computed from balance sheet or income statement figures are most commonly used for this purpose, the cash flow statement is a further key financial report to study short-term solvency, especially to assess liquidity, in other words, if the operating cash inflows exceed the operating cash outflows in the two differentiated wine-growing areas object of this study. Cash flow from operating activity is reported to be a key determinant of firm survivability (Arimany-Serrat \& Farreras-Noguer, 2020; Arimany-Serrat et al., 2016; Bresciani et al., 2016; Rondós Casas et al., 2018). In this article we study the liquidity of large companies in the sector for which the cash flow statement is compulsory (meeting two of the three following conditions: annual turnover greater than 8 million EUR; total assets greater than 4 million EUR and more than 50 employees). There has been a long on-going debate about the quality of statistical analyses based on financial ratios (e.g. * Corresponding author. Tel. +34972418736

E-mail address: germa.coenders@udg.edu (G. Coenders) 
Faello, 2015; Lev \& Sunder, 1979; Linares-Mustarós et al., 2018). In order to make the liquidity diagnostic in the wine sector more robust, in this article we complement the conventional methodology of liquidity analysis (short-term solvency ratio, cash flow from operating activity and operating cash flow ratio) with the Compositional Data (CoDa) methodology. The CoDa methodology overcomes the statistical problems arising from classical financial ratios (mainly asymmetry and outliers), which makes it more accurate in sectoral or regional financial statement studies, a point which is confirmed with the data used in this article. To the best of our knowledge, the CoDa methodology has never been applied to the cash flow statement. The wine sector is an important asset for the Spanish economy as it represents $1 \%$ of GDP. Spain has 969,000 hectares of vineyards ( $13 \%$ of the world total), is the world's third largest producer (44.4 million hectolitres in 2018), the world's largest exporter in volume and third largest in value (more than 21 million hectolitres and 2.7 billion EUR in 2019) and is responsible for $25 \%$ of wine produced in Europe, in addition to generating direct and indirect employment in the different Spanish territories.

The two wine-growing areas analysed are relevant for their quantitative and qualitative importance in the Spanish context. The Catalonia autonomous region integrates 8,500 winegrowers, 55,000 hectares, 800 wineries, 6,000 employees and 11 protected designations of origin (PDOs) including the world renowned Priorat and Penedès, and with the sparkling wine termed "cava" as key export. It should be noted that the Catalan government provides 5.3 million EUR aid to wine growers, wineries and wine PDOs, to cover the value chain of the sector; with a desire to promote the production of rectified concentrated must, and to reduce the surplus of grapes, in line with the circular bioeconomy.

The small La Rioja autonomous region hosts one single PDO which is the leading one in Spain. Given this fact, the wine sector has a huge weight in the direct and indirect employability in the area in relative terms, and integrates more than 600 wineries, 14,800 winegrowers, 65,000 hectares, the largest barrel park in the world, and exports to 130 different countries.

The article is organized as follows. We first explain the methodology, both in terms of classical financial statement analysis and compositional financial statement analysis with their similarities and differences, and their interpretation. Next, we present and discuss the main results of both analyses, in what is complementary and in what is different. The article ends with a concluding section.

\section{Material and methods}

\subsection{Statistical issues with financial ratios}

Standard financial ratios have long been reported to be liable to a number of serious statistical problems, such as asymmetry, outliers, non-linearity, and even dependence of the results on the arbitrary decision regarding which accounting figure appears in the numerator and which in the denominator (Carreras-Simó \& Coenders, 2020; 2021; Cowen \& Hoffer, 1982; Creixans-Tenas et al., 2019; Faello, 2015; Frecka \& Hopwood, 1983; Lev \& Sunder, 1979; Linares-Mustarós et al., 2018; Saus-Sala et al., 2021; So, 1987). These serious problems have also been reported in other scientific fields using ratios (Isles, 2020). The CoDa methodology is a standard toolbox for analysing ratios among magnitudes, (Aitchison, 1986; van den Boogaart \& Tolosana-Delgado, 2013; Filzmoser et al., 2018; Greenacre, 2018; Pawlowsky-Glahn et al., 2015) which is specialised in solving the aforementioned problems. Far from being a statistical refinement, the CoDa methodology leads to very substantial differences in the analysis results whenever they have been compared with standard financial ratios (Carreras-Simó \& Coenders, 2021; Linares-Mustarós et al., 2018).

The CoDa methodology was born in the fields of chemistry and geology to treat the fixed-sum data often arising from chemical analyses. CoDa are contemporarily defined in more practical and general terms as any arrays of strictly positive numbers for which ratios between them are considered to be relevant (Egozcue \& Pawlowsky-Glahn, 2019). Financial statement analysis fulfils this definition to the letter. This broader definition spurred a widespread usage, and CoDa quickly embraced many other scientific fields, including the social sciences in general (Coenders \& Ferrer-Rosell, 2020) and finance in particular. Examples of the latter are crowdfunding (Davis et al., 2017), financial markets (Ortells et al., 2016), municipal budgeting (Voltes-Dorta et al., 2014), portfolios (Boonen et al., 2019), insurance pricing (Verbelen et al., 2018), and currency exchange markets (Gámez-Velázquez \& Coenders, 2020; Maldonado et al., 2019; 2021). Financial statement analysis has embraced the CoDa methodology only recently (Carreras-Simó \& Coenders, 2020; 2021; Creixans-Tenas et al., 2019; Linares-Mustarós et al., 2018; Saus-Sala et al., 2021), and, to the best of our knowledge, never with a focus on liquidity analysis or using the statement of cash flows.

\subsection{Accounting figures as CoDa}

CoDa are positive vector variables carrying information about the relative size of their $D$ components $\left(x_{j}\right)$ to one another (Aitchison, 1986):

$$
\mathbf{x}=\left(x_{1}, x_{2}, \ldots, x_{D}\right) \text { with } x_{j}>0, j=1,2, \ldots, D
$$


When using compositions for the purpose of financial statement analysis the $x_{j}$ components in vector $\mathbf{x}$ are purposely selected positive figures from the financial statements. Even if sometimes standard financial ratios involve accounting figures which may be negative, its use is advised against in the accounting literature, because they can cause a discontinuity, outliers, or even a reversal of interpretation (Creixans-Tenas et al., 2019; Lev \& Sunder, 1979; Linares-Mustarós et al., 2018). It is also advised against from the point of view of measurement theory. Computing a ratio is a meaningful operation only for variables in a ratio scale, which need to have a meaningful absolute zero (Stevens, 1946) and thus no negative values. In general, accounting figures are negative because they imply some form of subtraction. In their stead, one should use the original non-negative figures being subtracted, without loss of information, as shown below. This is why we treat cash flow from operating activities by reverting back to cash inflows and cash outflows.

In this article we consider the following $D=4$ positive figures from the balance sheet and the cash flow statement (in million EUR):

$x_{1}$ cash inflows from operating activities

$x_{2}$ cash outflows from operating activities

$x_{3}$ current assets

$x_{4}$ current liabilities

The figures $x_{1}$ to $x_{4}$ are enough to compute the most common classic short-term solvency and liquidity indicators in a broad sense, not only ratios (Almamy et al., 2016; Casey \& Bartczak, 1985; Das, 1919; Kirkham, 2012; Shakatreh, 2021):

$$
\begin{aligned}
& r_{1}=\text { operating cash flow ratio }=\left(x_{1}-x_{2}\right) / x_{4} . \\
& r_{2}=\text { cash flow from operating activities }=x_{1}-x_{2} . \\
& r_{3}=\text { short term solvency ratio }=\text { current ratio }=x_{3} / x_{4} .
\end{aligned}
$$

In the next section we present their compositional counterparts.

\subsection{Transformations in CoDa}

The usual CoDa approach for solving the statistical problems involved in standard ratios, is to use existent standard statistical methods on transformed data. Logarithms of ratios are the standard transformation in CoDa (Pawlowsky-Glahn et al., 2015). A log-ratio involving only two components is computed as:

$$
y=\log \left(\frac{x_{j}}{x_{k}}\right) \text {. }
$$

The advantages of log-ratios over standard ratios can be summarized as follows (Linares-Mustarós et al., 2018). Unlike a standard ratio, which is bounded between zero and infinity, a log-ratio is symmetric in the sense that its range is from minus infinity to plus infinity. It is also symmetric in the sense that permuting the numerator and denominator components affects no other property of the log-ratio than the sign. Thus, using the current liability to current asset ratio instead of the current asset to current liability ratio, as sometimes done, will not modify the statistical inference results. Furthermore, if one of the components being compared is close to zero, it may lead to an outlying standard ratio when placed in the denominator. Finally, the information about the sign of the subtraction of $x_{j}$ and $x_{k}$, if of interest, is recovered by the log-ratio. The logratio is positive if $x_{j}>x_{k}$ and negative if $x_{j}<x_{k}$.

Among log-ratios, the so-called isometric log-ratio (ilr) coordinates (Egozcue et al., 2003) are most often recommended on the grounds that they are usable in virtually any statistical analysis (Carreras-Simó \& Coenders, 2021; Linares-Mustarós et al., 2018). Ilr coordinates can be easily formed from a sequential binary partition (SBP) of components. To create the first ilr coordinate, the complete composition $\mathbf{x}=\left(x_{1}, x_{2}, \ldots, x_{D}\right)$ is split into two groups of components: one for the numerator and the other for the denominator of the log-ratio. In the following step, one of the two groups is further partitioned to create the second ilr coordinate. In any step of the SBP, when the $y_{j}$ ilr coordinate is created, a group containing $r+s$ components is split into two: $r$ components $\left(x_{n l}, \ldots, x_{n r}\right)$ are placed in the numerator, and $s$ components $\left(x_{d l,}, \ldots, x_{d s}\right)$ in the denominator. The ilr coordinate is a scaled log-ratio of the geometric means of each group of components:

$$
y_{j}=\sqrt{\frac{r s}{r+s}} \log \frac{\sqrt[r]{x_{n 1} \ldots x_{n r}}}{\sqrt[s]{x_{d 1} \ldots x_{d s}}}
$$


A positive sign of the coordinate implies greater importance of the components in the numerator as compared to those in the denominator. $\sqrt{\frac{r s}{r+s}}$ is only a scaling constant used to take the number of components involved into account. It must be noted that $D$ components always result in $D-1$ coordinates.

It is advisable to choose a SBP which can be interpreted in the light of the usual concepts in liquidity analysis, which lends itself to building analogues to known standard ratios such as the cash flow ratio and the current ratio. The SBP is often represented as a sign matrix, in which each row is a partition in descending order, positive signs represent components in the numerator, negative signs components in the denominator, and blank spaces components not participating in the partition.

$$
\begin{array}{lllll} 
& x_{1} & x_{2} & x_{3} & x_{4} \\
y_{1} & + & + & - & - \\
y_{2} & + & - & & \\
y_{3} & & & + & -
\end{array} .
$$

At the top of the SBP we separate the cash flow statement, in the numerator (cash inflows from operating activities - $x_{l^{-}}$and cash outflows from operating activities $-x_{2}$ ) from the balance sheet, in the denominator (current assets - $x_{3^{-}}$and current liabilities $-x_{4}$ ). As $r_{1}$, the $y_{1}$ coordinate compares the cash flow constituents with some balance sheet figure, but their similarity ends here. More precisely, $y_{l}$ can be formulated in several ways:

$$
y_{1}=\sqrt{\frac{4}{4}} \log \frac{\sqrt[2]{x_{1} x_{2}}}{\sqrt[2]{x_{3} x_{4}}}=\frac{1}{2} \log \frac{x_{1}}{x_{4}}+\frac{1}{2} \log \frac{x_{2}}{x_{3}}=\frac{1}{2} \log \frac{x_{1}}{x_{3}}+\frac{1}{2} \log \frac{x_{2}}{x_{4}}
$$

and can be interpreted in terms of conversion and payment cycles. The higher the $y_{l}$ coordinate, the more times cash inflows in one year are able to pay for the end-of-year current liabilities, and the more times cash outflows in one year pay for the end-of-year current assets. It can also be interpreted in terms of cash inflows generated by unit of current assets, and as cash outflows involved per unit of current liabilities. A higher figure shows a more efficient asset use and shorter payment cycles, and thus firms which perform better in generating cash flows, as long as inflows exceed outflows, which is indicated by another coordinate defined below. In this manner, a higher $y_{l}$ value amplifies the benefits from positive operating cash flows, but also amplifies the liquidity stress resulting from negative operating cash flows. The $y_{l}$ coordinate thus falls into the category of the so-called turnover ratios or efficiency ratios. To the best of our knowledge this is the first usage of the cash flow statement to construct efficiency ratios. The second partition compares cash inflows from operating activities $\left(x_{l}\right)$ and cash outflows from operating activities $\left(x_{2}\right)$ :

$$
y_{2}=\sqrt{\frac{1}{2}} \log \left(\frac{x_{1}}{x_{2}}\right)
$$

Taking into account the log scale, a positive $y_{2}$ coordinate shows inflows to be larger than outflows. The further the $y_{2}$ coordinate is from zero, the larger the difference between inflows and outflows, in relative terms. Compared to the usual approach of computing operating cash flow by subtracting $x_{1}$ and $x_{2}$ as in $r_{2}$, we add the notion of relative difference between inflows and outflows. A firm with $x_{1}=1,000$ and $x_{2}=500$ is certainly much better off than a firm with $x_{1}=10,000$ and $x_{2}$ $=9,500$, as witnessed by their respective $y_{2}$ values 0.490 and 0.036 , even if their $r_{2}$ values are the same. The third partition compares current assets $\left(x_{3}\right)$ and current liabilities $\left(x_{4}\right)$ and is interpreted exactly as the standard current ratio $r_{3}$, in a log scale. If $y_{3}$ equals zero, the standard current ratio equals one. Larger $y_{3}$ values indicate larger short-term solvency according to the current ratio:

$$
y_{3}=\sqrt{\frac{1}{2}} \log \left(\frac{x_{3}}{x_{4}}\right) .
$$

Summing up, higher values of $y_{1}$ and $y_{3}$, together with positive values of $y_{2}$ indicate better liquidity, as do higher $r_{1}, r_{2}$ and $r_{3}$ values. From here onwards we refer to the $y_{1}$ to $y_{3}$ coordinates as compositional financial ratios, compositional financial indicators or, in more precise terms, compositional liquidity ratios.

Once ilr coordinates have been computed, statistical analysis can be made with standard methods and software. The analyses in this article involve the description of the evolution of the three compositional and standard financial indicators along 
time, while testing for the significance of differences between consecutive years and between regions. We use the $\mathrm{R}$ base, graphics, stats and RcmdrMisc packages.

\subsection{Data}

The balance sheet and cash flow statement data were obtained from the SABI (Iberian Balance sheet Analysis System, accessible at https://sabi.bvdinfo.com/) database, developed by INFORMA D\&B in collaboration with Bureau Van Dijk. Search criteria were active firms between 2014 and 2018 in the Catalonia and La Rioja autonomous regions, Spain, belonging to the NACE Rev. 2 classification code 11.02 "manufacture of wine form grape" (Eurostat, 2008), fulfilling at least two of the following three conditions which make the cash flow statement compulsory: sales above 8 million EUR, assets above 4 million EUR and over 50 employees.

Firms which had data for only one year were removed from the sample. 45 firms were kept for analysis (27 in Catalonia, and 18 in La Rioja). The number of firms providing data for each year is 40 in 2014, 44 in 2015, 44 in 2016,45 in 2017 , and 36 in 2018. 32 firms had complete data for all five years, 11 for four years, 1 for three years and 1 for two years. The number of observations is thus $n=209$.

Regarding the last year analysed, the sample under study has $53 \%$ of companies with fewer than 50 employees, while only $13 \%$ exceed 100 employees. Regarding their legal form $83 \%$ are capital companies with the legal forms of public limited company and private limited company, while $17 \%$ are cooperatives. Regarding their assets, $66 \%$ are below 50 million EUR and $14 \%$ exceed 100 million EUR. $85 \%$ of companies in the sample have profits, and $15 \%$ have losses.

According to the current 2007 General Accounting Plan in Spain, the indirect method is used for the cash flow statement, which implies not reporting operating cash inflows $\left(x_{1}\right)$ and outflows $\left(x_{2}\right)$ separately but only operating cash flows $\left(x_{1}-x_{2}\right)$. In our study, the cash inflows $\left(x_{1}\right)$ have been the result of integrating income that implies a cash inflow, changes in current capital and the charges of interest and other charges by all the companies observed. In particular, to the net sales, we have added the variation of the inventories of finished products and products in progress, the work carried out for fixed assets, other operating income, other incomes, financial income, and the variation in debtors and other accounts receivable and other current assets. Cash outflows $\left(x_{2}\right)$ are then deduced from the reported operating cash flows $\left(x_{1}-x_{2}\right)$.

\section{Results}

\subsection{Symmetry, non-linearity and outliers}

The skewness coefficients show much larger asymmetry for the standard indicators $r_{l}$ to $r_{3}$ (Table 1). The box plots in Fig. 1 also show $y_{1}$ to $y_{3}$ to generally have fewer outliers than $r_{1}$ to $r_{3}$. In the same vein, scatterplots (Fig. 2) show $y_{1}$ to $y_{3}$ to generally have closer to linear relationships than $r_{l}$ to $r_{3}$. Summing up, the compositional ratios are much more appropriate for statistical analysis than the standard indicators.

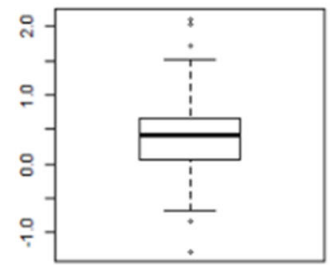

y1

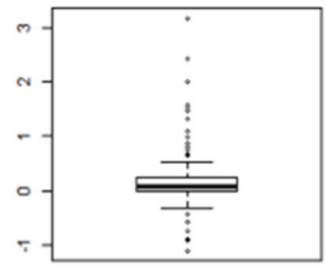

11

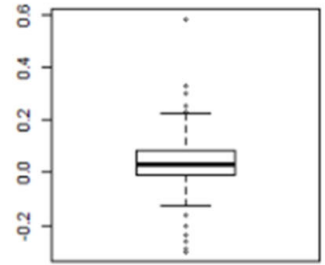

y2

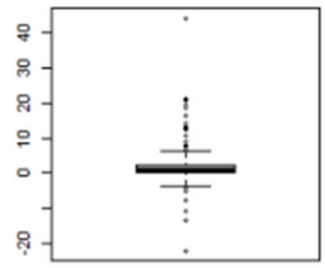

12

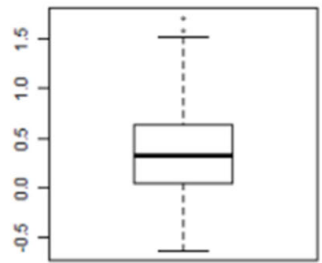

y3

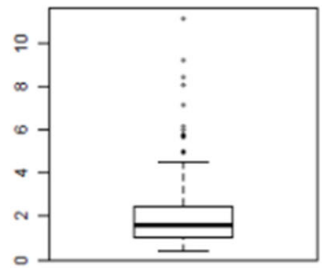

B

Fig. 1. Box plots of the standard indicators $r_{1}$ to $r_{3}$ and compositional indicators $y_{1}$ to $y_{3}$ 
Table 1

Skewness and kurtosis of the standard indicators $r_{1}$ to $r_{3}$ and compositional indicators $y_{1}$ to $y_{3}$

\begin{tabular}{lllllll}
\hline & $y_{1}$ & $r_{1}$ & $y_{2}$ & $r_{2}$ & $y_{3}$ & $r_{3}$ \\
\hline Skewness & 0.14 & 2.72 & 0.56 & 2.46 & 0.51 & 2.36 \\
Kurtosis & 0.98 & 13.50 & 5.03 & 17.05 & 0.11 & 6.77 \\
\hline
\end{tabular}
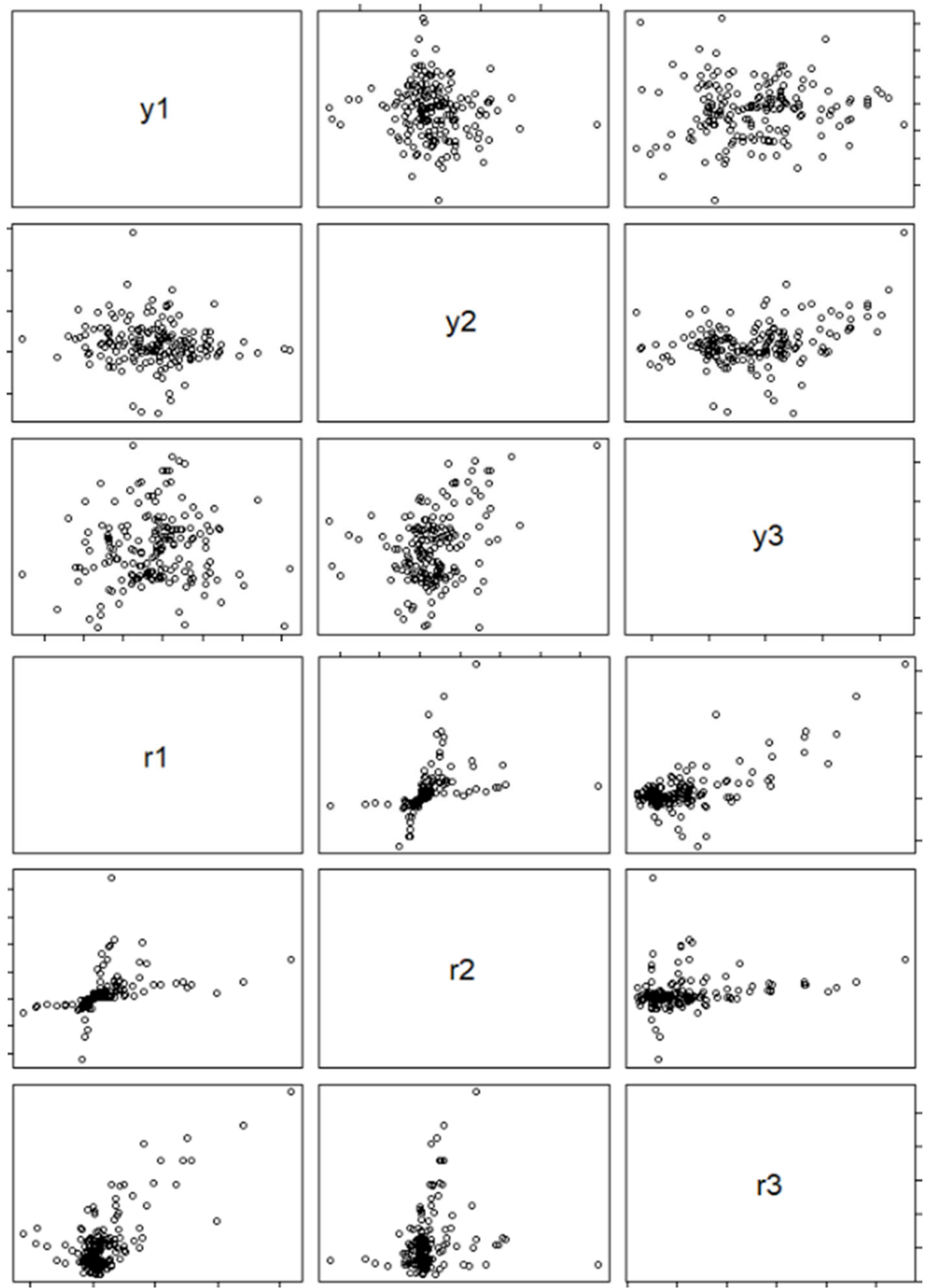

Fig. 2. Scatterplot matrix of the standard indicators $r_{1}$ to $r_{3}$ and compositional indicators $y_{1}$ to $y_{3}$.

\subsection{Significance of differences between regions}

The means of the compositional and standard indicators by region and year are in Table 2 .

The means should be interpreted with great caution for standard financial indicators due to asymmetry and outliers. For a more visual presentation, confidence intervals can be plotted around the means in Table 2, which, again, are not reliable for the standard-indicator case. Following Goldstein and Healy (1995), when intervals drawn with $83 \%$ confidence do not overlap, there is a significant difference at $95 \%$ confidence between the two regions (Fig. 3 ). 
Table 2

Means of the standard indicators $r_{1}$ to $r_{3}$ and compositional indicators $y_{1}$ to $y_{3}$ by year and region

\begin{tabular}{|c|c|c|c|c|c|c|c|}
\hline & & $y_{1}$ & $r_{1}$ & $y_{2}$ & $r_{2}$ & $y_{3}$ & $r_{3}$ \\
\hline 2014 & $\mathrm{C}$ & 0.32 & 0.00099 & 0.0107 & -0.56 & 0.19 & 1.5 \\
\hline 2014 & $\mathrm{R}$ & 0.24 & 0.35071 & 0.0789 & 2.08 & 0.44 & 2.3 \\
\hline 2015 & $\mathrm{C}$ & 0.50 & -0.00044 & 0.0018 & 0.33 & 0.21 & 1.5 \\
\hline 2015 & $\mathrm{R}$ & 0.35 & 0.35581 & 0.0845 & 3.16 & 0.60 & 2.9 \\
\hline 2016 & $\mathrm{C}$ & 0.48 & 0.17084 & 0.0293 & 3.47 & 0.25 & 1.9 \\
\hline 2016 & $\mathrm{R}$ & 0.42 & 0.30457 & 0.0705 & 2.33 & 0.63 & 2.9 \\
\hline 2017 & $\mathrm{C}$ & 0.33 & 0.05264 & 0.0397 & 2.69 & 0.23 & 1.7 \\
\hline 2017 & $\mathrm{R}$ & 0.28 & 0.24403 & 0.0645 & 1.83 & 0.65 & 2.9 \\
\hline 2018 & $\mathrm{C}$ & 0.45 & -0.01631 & 0.0059 & 1.17 & 0.33 & 2.0 \\
\hline 2018 & $\mathrm{R}$ & 0.37 & 0.31061 & 0.0573 & 2.06 & 0.60 & 2.8 \\
\hline
\end{tabular}

Notes: C indicates Catalonia and R La Rioja.

These significant differences stand in conflict between the standard and compositional financial ratios, partly due to outliers and asymmetry and partly to the differences in interpretation. The $r_{2}$ values, which refer to absolute cash flow figures, can indicate both cash flow generating capacity and firm size, which is not the case for $y_{2}$. In this respect, the interpretation of $y_{2}$ more closely mirrors that of $r_{1}$, which, being a ratio, controls for firm size. $y_{3}$ and $r_{3}$ are interpreted in exactly the same way, so that their differences in statistical significance in 2016 are only due to outliers and asymmetry. None of the standard indicators mirrors the interpretation of $y_{l}$ as a turnover or efficiency ratio related to cash flow. In our opinion, the compositional alternative provides both a more robust liquidity diagnostic, from a statistical standpoint, and a richer one, from an accounting standpoint.
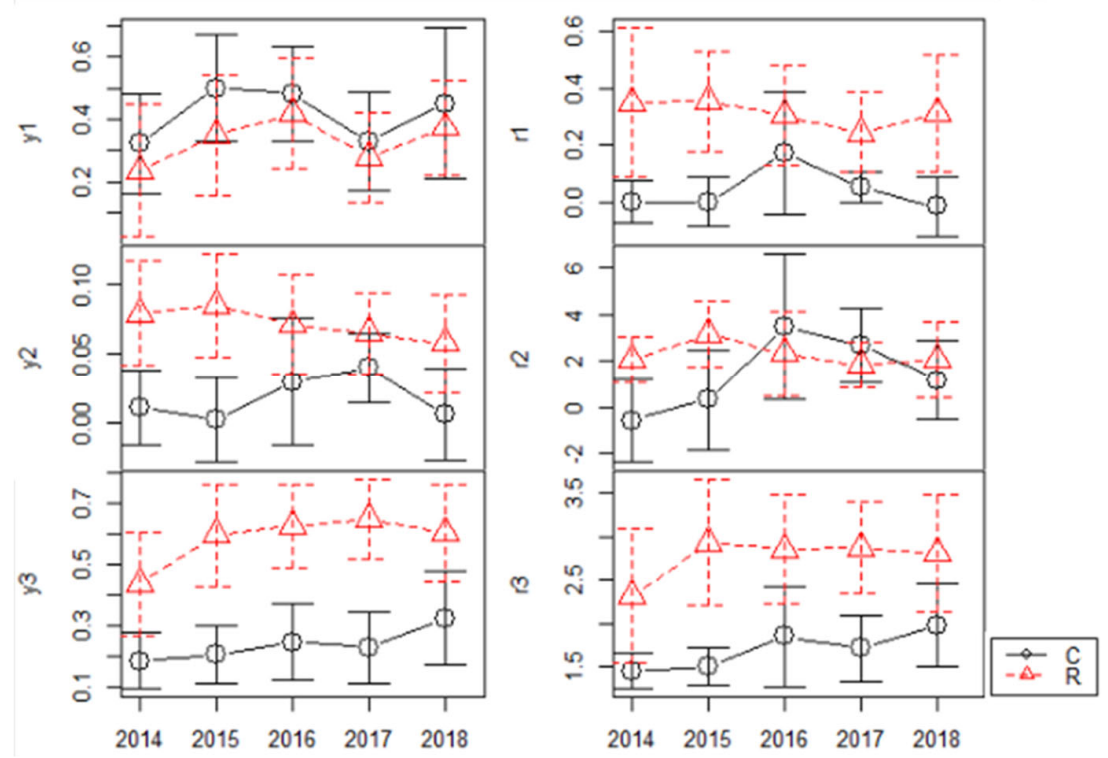

Fig. 3. Confidence intervals for the means of the standard indicators $r_{1}$ to $r_{3}$ and compositional indicators $y_{1}$ to $y_{3}$ by year and region

Notes: C indicates Catalonia and R La Rioja. Non overlapping intervals between regions for a given year show significant differences at $95 \%$ confidence.

We interpret the significant differences in means according to the compositional liquidity ratios $y_{1}$ to $y_{3}$ only, which are symmetric and do not have extreme outliers. Wineries in La Rioja have a significantly higher mean $y_{2}$ in 2014 and 2015 , thus showing larger cash operating inflows, compared to outflows, in relative terms. Wineries in La Rioja have a significantly larger mean $y_{3}$ between 2015 and 2017, and thus a higher current ratio. Taken together, the results in $y_{2}$ and $y_{3}$ show wineries in La Rioja to have better liquidity than those in Catalonia.

Fig. 4 shows the scatterplot of $y_{1}$ and $y_{2}$, whose interpretation is complementary. The liquidity diagnostic is best for firms with a high excess of cash inflows over outflows (positive $y_{2}$, in the upper part of the graph) coupled with large cash flow figures as compared with current assets and current liabilities (large $y_{l}$, in the right part of the graph). These data points correspond mainly to La Rioja. The liquidity diagnostic is worst for firms with a high excess of cash outflows over inflows (in the lower part of the graph) coupled with large cash flow figures as compared with current assets and current liabilities (in the right part of the graph). These data points correspond mainly to Catalonia. In terms of policy implications, for such firms with high turnover it is especially important to keep payments down in order to achieve a positive cash flow figure. 
Firms close to zero in the vertical axis or to the left of the graph, are those for which cash flow acts in a rather neutral fashion, with small relative differences between inflows and outflows, or at least small as compared to current assets and current liabilities. The firms belonging to La Rioja in the lower left quadrant of the graph constitute good examples. Catalan wineries in the upper left quadrant constitute also good examples. Firms in this quadrant would improve their liquidity by just increasing their turnover.

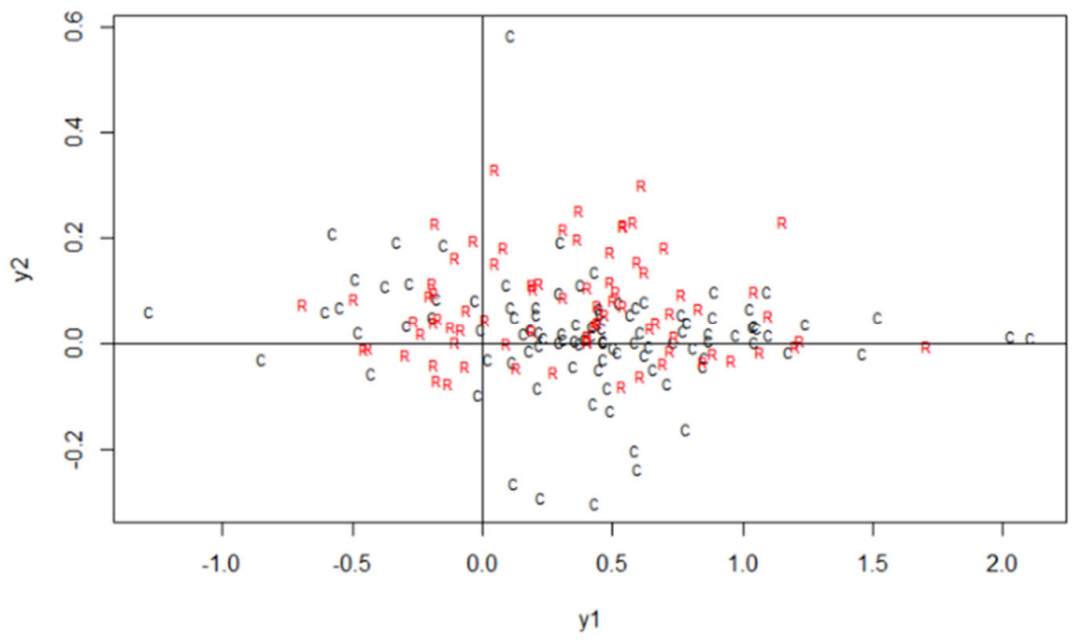

Fig. 4. Scatterplot of the compositional indicators $y_{1}$ and $y_{2}$ by region Notes: C indicates Catalonia and R La Rioja.

The novel proposal for a joint interpretation of $y_{1}$ and $y_{2}$ brings in a richer view than the usual interpretation based on cashflows alone, pointing out firms which may be substantially better or worse-off, in spite of having a similar cash flow.

\subsection{Significance of differences along time}

The confidence intervals for means in Fig. 3 cannot be used to find significant differences between consecutive years because data are paired. In their stead, we use a panel linear regression model with firm and time fixed effects, which rely on less stringent assumptions than their random-effect counterparts (Croissant \& Millo, 2019). Time dummy variables are coded in different ways in order to test for differences between consecutive years, differences between the first and the last year and differences between the first two years and the last two years. The only significant $(\alpha=5 \%)$ change we observe is a decrease in the compositional indicator $y_{1}$ between 2016 and 2017 in other words a decrease in the cash-flow generation efficiency ( $\mathrm{t}$-value $=-2.46$; $\mathrm{p}$-value $=0.015$ ). We find no significant change for standard indicators, whose results are in any case questionable due to outliers. Conclusions derived from standard indicators thus stand once more in contradiction with those obtained from compositional indicators.

\subsection{Valid results for standard financial ratios}

Even if standard financial indicators tend to be problematic when submitted to statistical analyses, there is no problem in interpreting them for individual firms. The firm in the middle when ordering the indicator values is the median (Table 3), which is a robust statistical measure to asymmetry and outliers. As was done for means, medians are best presented graphically, along time and per region (Fig. 5). The overall picture is that the median firm in La Rioja has better liquidity than its Catalan counterpart. However, unlike Fig. 3, this representation does not tell about the significance of differences.

Classifying firms as being under liquidity distress leads to the same results using $r_{2}$ and $y_{2}$ or $r_{3}$ and $y_{3}$. Regarding cash flow from operating activities, there is not a functional relationship between $r_{2}$ and $y_{2}$, but both have the same sign, so that a cutoff point $r_{2}<0$ or $y_{2}<0$ will select the same firms. Conversely, there is a functional relationship between the standard and compositional current ratios $r_{3}$ and $y_{3}$ so that the same firms will be selected for any cut-off point. We consider firms with $r_{3}<1.5$ or, equivalently, with $y_{3}<\sqrt{ }(1 / 2) \log (1.5)$ to be under liquidity distress. As stated above, none of the standard indicators mirrors the interpretation of $y_{1}$. Table 4 shows the percentages of firms under liquidity distress following both criteria, individually and jointly. Generally speaking, a greater portion of wineries in Catalonia face a liquidity distress situation. Differences between regions are largest for $r_{3}$ and $y_{3}$. It must be pointed out that to a large extent firms with liquidity problems according to the operating cash flow and to the current ratio are not the same, as witnessed by the low proportions of firms fulfilling both criteria simultaneously. This serves to stress the fact that the cash flow statement brings in information on liquidity of wineries which is not contained in the current ratio. 
Table 3

Medians of the standard indicators $r_{1}$ to $r_{3}$ by year and region

\begin{tabular}{lllll}
\hline & & $r_{1}$ & $r_{2}$ & $r_{3}$ \\
\hline 2014 & $\mathrm{C}$ & 0.024 & 0.31 & 1.1 \\
2014 & $\mathrm{R}$ & 0.105 & 1.49 & 1.8 \\
2015 & $\mathrm{C}$ & 0.041 & 0.75 & 1.2 \\
2015 & $\mathrm{R}$ & 0.210 & 2.82 & 2.1 \\
2016 & $\mathrm{C}$ & 0.065 & 0.90 & 1.2 \\
2016 & $\mathrm{R}$ & 0.139 & 0.59 & 2.4 \\
2017 & $\mathrm{C}$ & 0.092 & 1.13 & 1.1 \\
2017 & $\mathrm{R}$ & 0.199 & 1.05 & 2.6 \\
2018 & $\mathrm{C}$ & 0.025 & 0.30 & 1.2 \\
2018 & $\mathrm{R}$ & 0.124 & 2.26 & 2.3 \\
\hline
\end{tabular}

Notes: C indicates Catalonia and R La Rioja.

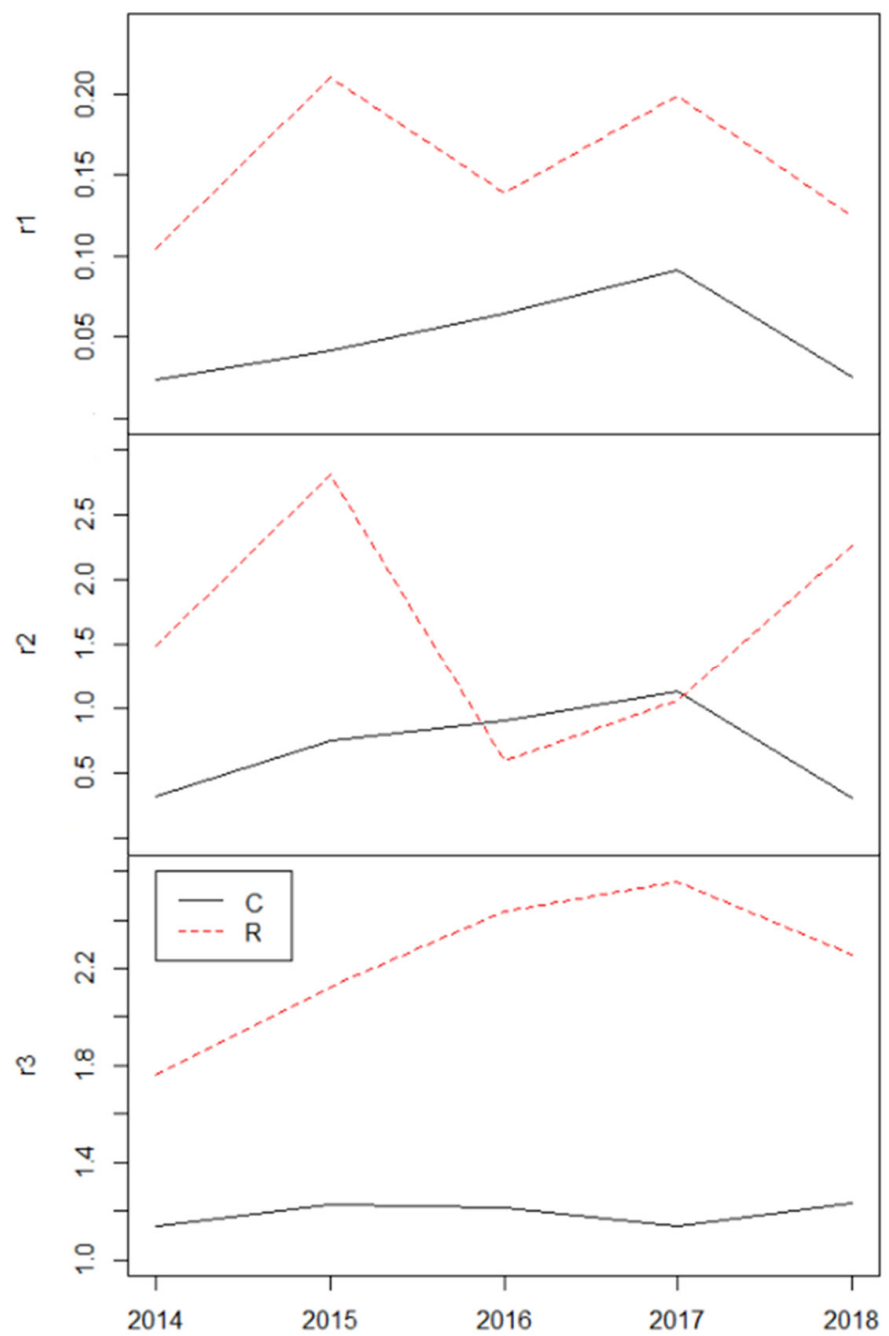

Fig. 5. Line plots for the median of the standard indicators $r_{1}$ to $r_{3}$ by year and region Notes: C indicates Catalonia and R La Rioja.

\section{Discussion}

Liquidity is a direct threat to financial health and can compromise the direct and indirect employability of the wine sector. This study highlights the short-term solvency problems of this sector in two relevant areas (Catalonia and La Rioja) over five years, to show the trend of the sector in terms of liquidity, using both conventional and compositional financial indicators. The study shows significant differences in the results between both approaches, and highlights the novel $y_{1}$ turnover indicator. 
Table 4

Percentage of firms under liquidity distress according to the cash flow and to the current ratio

\begin{tabular}{lllllll}
\hline & & 2014 & 2015 & 2016 & 2017 & 2018 \\
\hline$r_{2}<0, y_{2}<0$ & $\mathrm{C}$ & 42.1 & 28.6 & 30.4 & 19.0 & 35.3 \\
& $\mathrm{R}$ & 23.1 & 31.2 & 23.5 & 17.6 & 26.7 \\
$r_{3}<1.5, y_{3}<\sqrt{ }(1 / 2) \log (1.5)$ & $\mathrm{C}$ & 64.0 & 61.5 & 65.4 & 66.7 & 55.0 \\
& $\mathrm{R}$ & 26.7 & 27.8 & 22.2 & 22.2 & 25.0 \\
$r_{2}<0, y_{2}<0$ and & $\mathrm{C}$ & 25.0 & 16.7 & 16.7 & 4.4 & 15.8 \\
$r_{3}<1.5, y_{3}<\sqrt{ }(1 / 2) \log (1.5)$ & $\mathrm{R}$ & 14.3 & 17.6 & 0.0 & 5.9 & 6.7 \\
\hline
\end{tabular}

Notes: C indicates Catalonia and R La Rioja.

Conventional liquidity indicators (operating cash flow ratio; cash flow from operating activities and short-term solvency ratio) and homologous compositional indicators emphasize that compositional ratios allow researchers and professionals to perform a more accurate diagnosis of the liquidity of wineries, due to the very often reported outliers, asymmetry and nonlinearity in standard financial ratios. As Carreras-Simó and Coenders (2021), this study shows that the compositional indicators are more suitable for statistical analysis than the standard indicators, especially for analyses involving formal statistical inference. For instance, the significant differences in the two areas according to $y_{3}$ and $r_{3}$ are not the same due to asymmetry and outliers. Having said this, the compositional indicators are also suitable for descriptive sectoral analyses, and results are comparable to standard indicators, as shown in Table 4.

It should be borne in mind that no standard indicator carries the interpretation of $y_{1}$ as an indicator of turnover between operating cash inflows with respect to current investments and operating cash outflows with respect to current liabilities, as a complement to the diagnosis of the short-term solvency. According to the results of this article, the wineries of La Rioja tend to have more favourable cash flows than their Catalan counterparts, with high $y_{1}$ when $y_{2}>0$. On the contrary, Catalan companies have an excess of operating cash outflows, and once these Catalan companies have been identified, it can be seen that six particular wineries in Catalonia with low profits account for this situation. Thus, the joint interpretation of $y_{1}$ and $y_{2}$ refines the diagnosis of the goal set in this article.

Regarding the differences between regions, $y_{2}$ and $y_{3}$ are statistically significant, highlighting that the wineries of La Rioja have better liquidity than Catalan wineries, with higher operating income, translated into higher returns, in addition to having a single well-positioned PDO that favours exports and simplifies branding and distribution, as opposed to the 11 PDOs of Catalonia and the most recent Catalan export experience (Arimany-Serrat et al., 2016).

The limitations of this article include the following. On the one hand the SABI data base includes the cash flow statement only for large companies, while small companies are the most frequent in the sector and may be expected to have worse liquidity problems. Having said this, the methodological differences between classical and standard indicators emerge with firms of any size (Carreras-Simó \& Coenders, 2021; Linares-Mustarós et al., 2018). On the other hand, the analysis has only assessed the significance of differences between regions and along time, but any other statistical test or model would be feasible with the compositional indicators, and may be explored in further research. The analysis has only considered $D=4$ accounting figures, but any positive figure, whose ratios with other figures are of interest (e.g., cash inflows and outflows from financing or investing activities, non-current assets, non-current liabilities) can be included in the SBP, simply resulting in additional ilr coordinates (Linares-Mustarós et al., 2018). Further research should also assess the effects on liquidity of Covid-19 and eventual changes in the USA tariff rates in the Biden era. Having said this, our results already show that wineries in La Rioja are starting from a better situation to deal with future economic threats than their Catalan counterparts.

\section{Funding}

This work was supported by the Spanish Ministry of Science, Innovation and Universities/FEDER [grant number RTI2018095518-B-C21]; the Spanish Ministry of Health [grant number CIBERCB06/02/1002]; and the Government of Catalonia [grant numbers 2017SGR656, 2017SGR386, 2017SGR155].

\section{References}

Aitchison, J. (1986). The statistical analysis of compositional data. Monographs on statistics and applied probability. London: Chapman and Hall.

Almamy, J., Aston, J., \& Ngwa, L.N. (2016). An evaluation of Altman's Z-score using cash flow ratio to predict corporate failure amid the recent financial crisis: Evidence from the UK. Journal of Corporate Finance, 36, $278-285$.

Alonso, A.D., \& Liu, Y. (2012). Coping with changes in a sector in crisis: the case of small Spanish wineries. Journal of Wine Research, 23(1), 81-95.

Arimany-Serrat, N., \& Farreras-Noguer, M.A. (2020). A comparison of the wine sectors in Catalonia, La Rioja, LanguedocRoussillon and Emilia-Romagna. Journal of Intelligent \& Fuzzy Systems, 38(5), 5553-5563. 
Arimany-Serrat, N., Farreras-Noguer, M.A., \& Rabaseda-Tarrés, J. (2016). Economic and financial analysis of Rioja wine sector. Intangible Capital, 12(1), 268-294.

van den Boogaart, K.G., \& Tolosana-Delgado, R. (2013). Analyzing compositional data with R. Berlin: Springer.

Boonen, T., Guillén, M., \& Santolino, M. (2019). Forecasting compositional risk allocations. Insurance Mathematics and Economics, 84, 79-86.

Bresciani, S., Giacosa, E., Broccardo, L., \& Culasso, F. (2016). The family variable in the French and Italian wine sector. EuroMed Journal of Business, 11(1), 101-118.

Carreras-Simó, M., \& Coenders, G. (2020). Principal component analysis of financial statements. A compositional approach. Revista de Métodos Cuantitativos para la Economía y la Empresa, 29(1), 18-37.

Carreras-Simó, M., \& Coenders, G. (2021). The relationship between asset and capital structure: a compositional approach with panel vector autoregressive models. Quantitative Finance and Economics, 5(4), 571-590.

Casey, C., \& Bartczak, N. (1985). Using operating cash flow data to predict financial distress: Some extensions. Journal of Accounting Research, 23(1), 384-401.

Coenders, G., \& Ferrer-Rosell, B. (2020). Compositional data analysis in tourism. Review and future directions. Tourism Analysis, 25(1), 153-168.

Cowen, S.S., \& Hoffer, J.A. (1982). Usefulness of financial ratios in a single industry. Journal of Business Research, 10(1), $103-118$.

Creixans-Tenas, J., Coenders, G., \& Arimany-Serrat, N. (2019). Corporate social responsibility and financial profile of Spanish private hospitals. Heliyon, 5(10), e02623.

Croissant, Y., \& Millo, M. (2019). Panel data econometrics with R. Hoboken: Wiley.

Das, S. (2019). Cash flow ratios and financial performance: A comparative study. Accounting, 5(1), 1-20.

Davis, B.C., Hmieleski, K.M., Webb, J.W., \& Coombs, J.E. (2017). Funders' positive affective reactions to entrepreneurs' crowdfunding pitches: The influence of perceived product creativity and entrepreneurial passion. Journal of Business Venturing, 32(1), 90-106.

Egozcue, J.J., \& Pawlowsky-Glahn, V. (2019). Compositional data: the sample space and its structure. TEST, 28(3), 599638.

Egozcue, J.J., Pawlowsky-Glahn, V., Mateu-Figueras, G., \& Barceló-Vidal, C. (2003). Isometric logratio transformations for compositional data analysis. Mathematical Geology, 35(3), 279-300.

Eurostat (2008). NACE Rev. 2 - Statistical classification of economic activities in the European Community. Eurostat methodologies and working papers. Luxembourg: European Communities.

Faello, J. (2015). Understanding the limitations of financial ratios. Academy of Accounting and Financial Studies Journal, $19(3), 75-85$.

Filzmoser, P., Hron, K., \& Templ, M. (2018). Applied compositional data analysis with worked examples in R. New York: Springer.

Frecka, T.J., \& Hopwood, W.S. (1983). The effects of outliers on the cross-sectional distributional properties of financial ratios. Accounting Review, 58(1), 115-128.

Gámez-Velázquez, D., \& Coenders, G. (2020). Identification of exchange rate shocks with compositional data and written press. Finance, Markets and Valuation, 6(1), 99-113.

Goldstein, H., \& Healy, M.J. (1995). The graphical presentation of a collection of means. Journal of the Royal Statistical Society: Series A (Statistics in Society), 158(1), 175-177.

Greenacre, M. (2018). Compositional data analysis in practice. New York: Chapman and Hall/CRC press.

Guariglia, A., Liu, X., \& Song, L. (2011). Internal finance and growth: Microeconometric evidence on Chinese firms. Journal of Development Economics, 96(1), 79-94.

Isles, P.D.F. (2020). The misuse of ratios in ecological stoichiometry. Ecology, 01(11), e03153.

Kirkham, R. (2012). Liquidity analysis using cash flow ratios and traditional ratios: The telecommunications sector in Australia. Journal of New Business Ideas and Trends, 10(1), 1-13.

Lev, B., \& Sunder, S. (1979). Methodological issues in the use of financial ratios. Journal of Accounting and Economics, 1(3), 187-210.

Linares-Mustarós, S., Coenders, G., \& Vives-Mestres, M. (2018). Financial performance and distress profiles. From classification according to financial ratios to compositional classification. Advances in Accounting, 40, 1-10.

Maldonado, W.L., Egozcue. J.J., \& Pawlowsky-Glahn, V. (2019). No-arbitrage matrices of exchange rates: Some characterizations. International Journal of Economic Theory. doi: 10.1111/ijet.12249

Maldonado, W.L., Egozcue, J.J., \& Pawlowsky-Glahn, V. (2021). Compositional analysis of exchange rates, in: Daouia, A., Ruiz-Gazen, A. (Eds.), Advances in contemporary statistics and econometrics. Festschrift in honor of Christine Thomas-Agnan. Springer Nature, Cham, pp. 489-507.

Ortells, R., Egozcue, J.J., Ortego, M.I., \& Garola, A. (2016). Relationship between popularity of key words in the Google browser and the evolution of worldwide financial indices, in: Martín-Fernández, J.A., Thió-Henestrosa, S. (Eds.), Compositional data analysis. Springer proceedings in mathematics \& statistics, Vol. 187. Springer, Cham, pp. $145-166$.

Pawlowsky-Glahn, V., Egozcue, J.J., \& Tolosana-Delgado, R. (2015). Modeling and analysis of compositional data. Chichester: Wiley.

Rondós Casas, E., Linares Mustarós, S., \& Farreras Noguer, M.A. (2018). Expansion of the current methodology for the study of the short-term liquidity problems in a sector. Intangible Capital, 14(1), 25-34. 
Saus-Sala, E., Farreras-Noguer, M.À., Arimany-Serrat, N., \& Coenders, G. (2021). Compositional DuPont analysis. A visual tool for strategic financial performance assessment, in: Filzmoser, P., Hron, K., Martín-Fernández, J.A., PalareaAlbaladejo, J. (Eds.), Advances in compositional data analysis. Festschrift in honour of Vera Pawlowsky-Glahn. Springer Nature, Cham, pp. 189-206.

Sellers-Rubio, R. (2010). Evaluating the economic performance of Spanish wineries. International Journal of Wine Business Research, 22(1), 73-84.

Shakatreh, M. (2021). The effect of liquidity ratios management on the profitability of industrial companies listed on the Amman Stock Exchange. Accounting, 7(5), 1131-1138.

Simon-Elorz, K., Castillo-Valero, J.S., \& Garcia-Cortijo, M.C. (2015). Economic performance and the crisis: strategies adopted by the wineries of Castilla-La Mancha (Spain). Agribusiness, 31(1), 107-131.

So, J.C. (1987). Some empirical evidence on the outliers and the non-normal distribution of financial ratios. Journal of Business Finance \& Accounting, 14(4), 483-496.

Stevens, S.S. (1946). On the theory of scales of measurement. Science, 103(2684), 677-680.

Verbelen, R., Antonio, K., \& Claeskens, G. (2018). Unravelling the predictive power of telematics data in car insurance pricing. Journal of the Royal Statistical Society: Series C (Applied Statistics), 67(5), 1275-1304.

Voltes-Dorta, A., Jiménez, J.L., \& Suárez-Alemán, A. (2014). An initial investigation into the impact of tourism on local budgets: A comparative analysis of Spanish municipalities. Tourism Management, 45, 124-133.

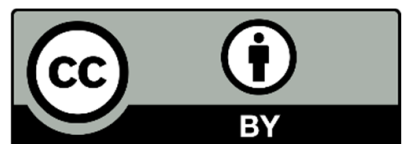

(C) 2022 by the authors; licensee Growing Science, Canada. This is an open access article distributed under the terms and conditions of the Creative Commons Attribution (CC-BY) license (http://creativecommons.org/licenses/by/4.0/). 